\title{
Altered apoptosis in bronchoalveolar lavage lymphocytes after allergen exposure of atopic asthmatic subjects
}

\author{
M. Müller*, J. Grunewald*, C. Olgart Höglund*,* B. Dahlén*, \\ A. Eklund* and H. Stridh*,
}

ABSTRACT: The increased number of lymphocytes in airways during an asthmatic response is believed to be the result of increased recruitment of these cells. However, it is possible that a decreased apoptotic rate could also contribute to the increased number. The aim of the present study was to investigate whether allergen airway provocation influences the apoptotic phenotype of lung and peripheral blood lymphocytes (PBL) in subjects with atopic asthma.

Bronchoalveolar lavage (BAL) lymphocytes and PBL from 12 asthmatic subjects previously challenged with allergen $(n=7)$ or saline $(n=5)$ were exposed to the apoptotic stimulus tributyltin (TBT) in vitro and assayed for apoptosis.

Airway allergen provocation resulted in decreased sensitivity of BAL lymphocytes to TBTinduced apoptosis, with $42.2 \%$ (range $33.9-62.5 \%$ ) apoptotic cells before challenge versus $23.5 \%$ (range 15.3-42.4\%) after challenge, while PBL were unaffected. The increased apoptosis resistance correlated with higher numbers of Bcl-2-expressing lymphocytes. Interestingly, baseline caspase-3-like activity was significantly elevated in viable BAL lymphocytes compared with viable PBL, and was unaltered by allergen exposure.

In conclusion, allergen inhalation renders bronchoalveolar lavage lymphocytes more resistant to apoptosis while peripheral blood lymphocytes were not influenced at all, indicating that the apoptotic phenotype of airway lymphocytes may play a role in asthmatic inflammation.

KEYWORDS: Apoptosis, asthma, bronchoalveolar lavage, caspases, lymphocytes, tributyltin

$\mathbf{A}$ llergic asthma is a chronic disease in which allergen-induced inflammatory processes in the airways contribute to the development of symptoms and may eventually lead to remodelling of the airway tissue. Inflammation at the sites of target organs is a pathological feature of the disease process and among the various types of cells involved in tissue infiltration and damage are T-lymphocytes, i.e. one of the main effector cells priming the local ongoing allergic immune response [1]. These cells are involved in the local recognition of allergens, acting through secreting T-helper (Th)2 cytokines and thereby determining immunoglobulin (Ig)E synthesis and the mucosal recruitment of other inflammatory cells, such as neutrophils and eosinophils [2, 3]. Although knowledge of the initiation of the allergic response has rapidly expanded during recent years, little is known about how the inflammatory response develops into a chronic inflammation.

Previous studies have demonstrated that reduced apoptosis of T-cells may play a role in asthma pathogenesis [4, 5]. Apoptosis of lymphocytes was decreased at baseline levels in asthmatic subjects compared with normal controls and patients with obstructive pulmonary disease [6]. Additionally, T-cells from asthmatic subjects fail to undergo the normal degree of apoptosis following Fas receptor ligation, and CD45RO+ $\mathrm{T}$-cells in the inner airway wall of patients with mild and serve asthma were less apoptotic compared with controls [7, 8]. The observed insufficient T-cell apoptosis may interfere with clonal deletion and maintenance of tolerance, resulting in T-cell accumulation and contributing to the chronic inflammation of asthma. Thus, previous data indicate alterations in the apoptotic phenotype of cells involved in asthmatic inflammatory processes $[4,6,7]$. However, changes in apoptosis sensitivity following an allergen challenge are still elusive.

Apoptotic cell death results from the activation of an internally encoded suicide programme, which is induced by a variety of intrinsic and extrinsic signals and is an important tool in the regulation

\section{AFFILIATIONS}

Depts of *Medicine, Division of Respiratory Medicine, and \#Physiology and Pharmacology, Karolinska Institutet and Karolinska University Hospital, and

"Dept of Oncology and Pathology, Cancer Center Karolinska, Karolinska Institutet, Stockholm, Sweden.

\section{CORRESPONDENCE}

M. Müller

Dept of Medicine Division of Respiratory Medicine Lung Research Laboratory L4-01 Karolinska University Hospital 17176 Stockholm Sweden

Fax: 46851775451

E-mail: malin.muller@ki.se

Received:

October 102005

Accepted after revision:

May 202006

\section{SUPPORT STATEMENT}

The present study was supported by grants from the Swedish Medical Research Council, the Swedish Heart Lung Foundation, the King Oscar II Jubilee Foundation, Åke Wiberg Foundation and Karolinska Institutet (all Stockholm, Sweden) 
of the immune system. The amount of reactive T-cells in an immune response can be controlled by a process called "activation-induced cell death", which mainly involves the activation of death receptors such as Fas [9]. However, apoptosis of activated T-cells can also be induced independently of death receptor signalling by the induction of the mitochondrial pathway, which is activated by signals such as cytokine withdrawal or the presence of reactive oxygen species [10-12]. Death receptor-mediated apoptosis involves the recruitment of the initiator caspase- 8 , while the initiation of the mitochondrial pathway leads to the cytoplasmic release of pro-apoptotic factors from the mitochondrion and the subsequent activation of caspase- 9 [13, 14]. The caspases belong to a family of cysteine proteases, which play a central role in the transduction of apoptotic signals, either by cleaving and activating downstream caspases or by processing vital proteins that will lead to the death of the cell. Until recently, caspase-3 has been considered to be an exclusively pro-apoptotic protein whose activation has been believed to be the "point of no return" in the apoptotic pathway. However, new evidence has emerged, suggesting an additional role for caspase- 3 together with caspase- 8 in differentiation and proliferation of activated T-cells [15-21].

High caspase-3-like activity in nonapoptotic bronchoalveolar lavage (BAL) lymphocytes recovered from sarcoidosis patients has previously been demonstrated [22]. These lymphocytes were also shown to be highly resistant to mitochondrialmediated apoptosis induced by tributyltin (TBT) [22]. In the present study, allergen inhalation challenge of individuals with asthma was used to delineate the processes of apoptosis occurring in the inflammatory phase of asthma. As little is known about mitochondrial-induced apoptosis of airway lymphocytes in asthma, the current authors were particularly interested to investigate the impact of this pathway in these cells. Therefore the authors used TBT, a mitochondrial toxin that specifically triggers the mitochondrial pathway by loss of mitochondrial membrane potential and cytochrome $C$ release [23-25].

The BAL lymphocytes from asthmatic subjects provoked with allergen were more resistant to mitochondrial-mediated apoptosis, while no change in apoptosis sensitivity was evident in BAL lymphocytes obtained from subjects challenged with saline. The decreased apoptosis sensitivity in allergenexposed BAL lymphocytes was associated with a higher proportion of Bcl-2-expressing lymphocytes. Furthermore, BAL lymphocytes from all subjects had an elevated caspase3-like activity compared with peripheral blood lymphocytes (PBL), and airway exposure to allergen did not increase the activity further. These data indicate that airway inflammation in asthma is associated with a reduced apoptosis susceptibility of lung lymphocytes, which may lead to an enhanced survival of BAL lymphocytes and consequently prolonged inflammation.

\section{MATERIALS AND METHODS Subjects}

In total, 12 atopic patients (three male and nine female) aged 22-46 yrs (median 27 yrs) with a history of mild allergic asthma participated in the study. All were nonsmokers except one who was an ex-smoker. All subjects in the study population had previously documented reactions following allergen bronchoprovocation. The patients allergic to animals did not have pets of their own and were asked to avoid animal contact during the study period. Their asthma was stable and controlled solely with $\beta_{2}$-agonists taken as required. As an inclusion criterion in the study the forced expiratory volume in one second (FEV1) was required to be $>70 \%$ of predicted. Prior to the study, bronchial hyperresponsiveness to methacholine with a provocative dose causing a $20 \%$ fall in FEV1 (PD20) of $<2,530 \mu \mathrm{g}$ was demonstrated. The methacholine provocation test was performed as previously described [26]. Patient characteristics and clinical data before and after allergen provocation are presented in table 1 . The study was approved by the Ethical Committee at the Karolinska University Hospital (Stockholm, Sweden), and all subjects gave their written informed consent.

\section{Study design}

The study was performed out of the pollen season. Patients were blinded and administered either saline or an allergen (table 1) for which they had a positive history and radioallergosorbent result. The allergen extracts used were standardised and freeze-dried (Aquagen; ALK, Copenhagen, Denmark). PBL and BAL samples were obtained 2-3 weeks before (baseline) and 1 day after the allergen/saline challenge. The type of allergen used for challenge, cumulative allergen dose, peak drop during the early asthmatic reaction (EAR) and the PD20 values are presented in table 1 . All bronchial provocations were performed using a dosimeter-controlled jet nebuliser (Spira Electro 2; Respiratory Care Center, Hameenlinna, Finland). In brief, the allergen challenge was initiated by inhalation of dilutent. Provided that the FEV1 did not change $>10 \%$, allergen was inhaled every $15 \mathrm{~min}$ with half-log increments of the cumulated dose until the FEV1 dropped $\geqslant 20 \%$ from the post-dilutent baseline value [27]. The occurrence of any late asthmatic reactions (LAR) were examined by measurements of peak expiratory flow rates every waking hour during the first $24 \mathrm{~h}$ following challenge. The patients were instructed to make additional recordings if any airway symptoms occurred.

\section{$B A L$, differential cell count, separation and handling of cells}

BAL was performed as previously described [28, 29]. In brief, under local anaesthesia the flexible fibreoptic bronchoscope (Olympus BF type 1TR; Olympus Optical Co Ltd, Tokyo, Japan) was wedged into a middle lobe bronchus and sterile PBS solution at $37^{\circ} \mathrm{C}$ was instilled in five aliquots of $50 \mathrm{~mL}$. After each instillation, the fluid was gently aspirated and collected in a siliconised plastic bottle kept on ice. The BAL was strained through a Dracon net (Millipore, Cork, Ireland), centrifuged at $400 \times g$ for $10 \mathrm{~min}$ at $4^{\circ} \mathrm{C}$, and the cell pellet was resuspended in Roswell Park Memorial Institute (RPMI) 1640 medium (Sigma chemicals, St Louis, MO, USA). Cells were counted using a Bürker chamber and cell viability was determined by trypan blue exclusion. Peripheral blood mononuclear cells (PBMC) were obtained by Ficoll-Hypaque gradient centrifugation (Amersham Pharmacia Biotech, Uppsala, Sweden), washed three times in PBS and diluted in RPMI 1640. For differential cell counts, cytospins were prepared by cytocentrifugation (Cytospin 2; Shandon, Runcorn, UK) of 60,000 cells per slide at $20 \times g$ for $3 \mathrm{~min}$. In 


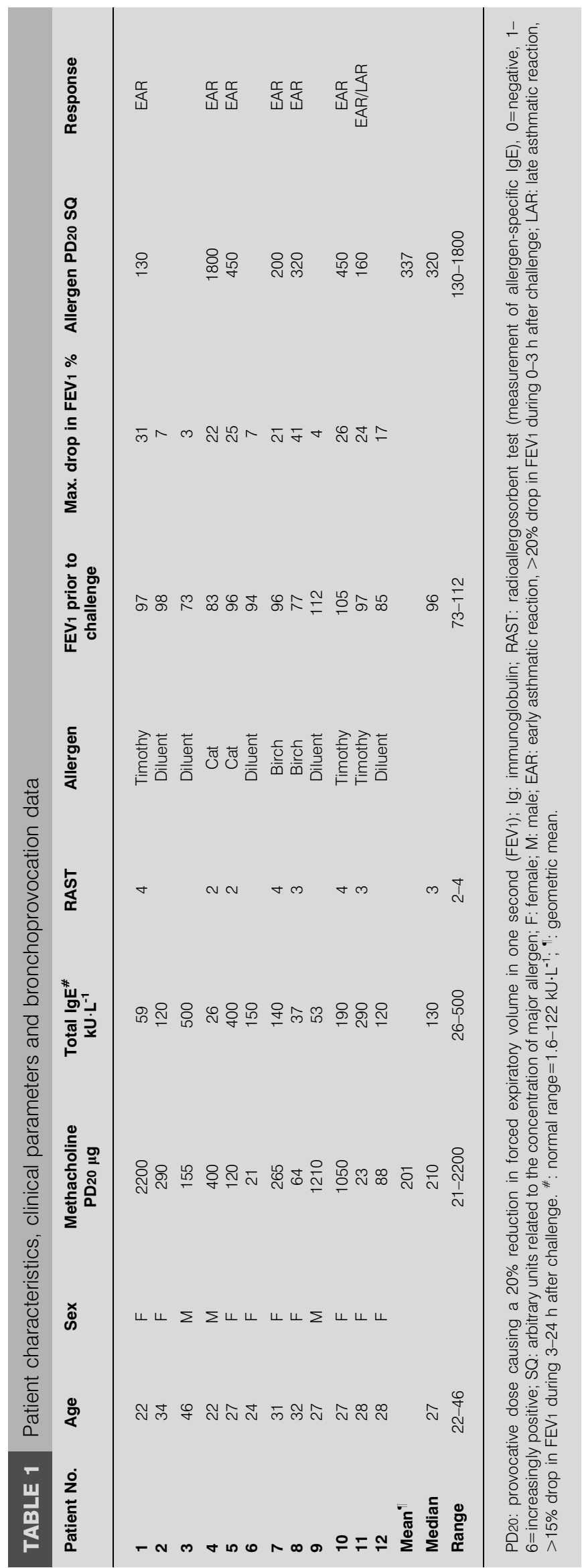

order to determine cell differentials, cytospin slides were stained with May-Grünwald-Giemsa and 400 cells were counted microscopically. Mast cells were stained using two parts toluidine blue $0.5 \%(\mathrm{pH} \quad 0.5)$ and one part $0.2 \%$ haematoxylin solution. The number of mast cells from 10 vision fields, at a magnification of $\times 16$, was counted microscopically. Both BAL cells and PBMC were kept on ice until the initiation of the experiments.

\section{Induction and detection of cell death}

BAL cells and PBMC were centrifuged at $400 \times g$ for $10 \mathrm{~min}$ at $4{ }^{\circ} \mathrm{C}$ and resuspended in complete medium at a concentration of $1 \times 10^{6}$ cells $\cdot \mathrm{mL}^{-1}$, complete medium (RPMI 1640 containing $5 \%$ foetal calf serum), $2 \mathrm{mM}$ L-Glutamine, penicillin $\left(100 \mathrm{U} \cdot \mathrm{mL}^{-1}\right)$ and streptomycin $\left(0.1 \mathrm{mg} \cdot \mathrm{mL}^{-1}\right.$; all Sigma Chemicals). Apoptosis was induced by exposure of the cells to $2 \mu \mathrm{M}$ TBT chloride (Sigma Aldrich, Munich, Germany) for $60 \mathrm{~min}$ at $37^{\circ} \mathrm{C}$ in a humidified air chamber with $5 \% \mathrm{CO}_{2}$. Dead cells were detected using fluorescein isothiocyanate (FITC)labelled annexin $\mathrm{V}$ and propidium iodide (PI; annexin V/PI; Pharmingen, San Diego, CA, USA) staining. Briefly, BAL cells and PBMC were resuspended in annexin-binding buffer containing annexin V-FITC and PI $\left(100 \mu \mathrm{g} \cdot \mathrm{mL}^{-1}\right)$ and incubated for $15 \mathrm{~min}$ at room temperature. The samples were analysed using a flow cytometer (FACS Calibur; Becton Dickinson, Franklin Lakes, NJ, USA). BAL lymphocytes and PBL were identified and gated by forward and side lightscattering properties. Ten thousand events were analysed and dot plots were used to determine the percentage of apoptotic cells showing annexin V-FITC (fluorescence (FL)-1 channel) binding; a minority of these cells were also permeable to PI (FL-3 channel). "Apoptotic cells" in the Results section refers to lymphocytes stained with annexin V, with or without PI staining, mainly including cells in early apoptosis (annexin V positive/PI negative; encompassing the vast majority of the cells) but also cells in late apoptosis (annexin $\mathrm{V}$ positive/PI positive; minority).

\section{Detection of caspase-3-like activity in intact cells}

Caspase-3-like activity in intact BAL and PBL was measured using the cell-permeable substrate PhiPhilux-G2D2 (OncoImmunin, Inc., Kensington, MD, USA), according to the manufacturer's recommendations. Briefly, cells were washed, resuspended in $50 \mu \mathrm{L}$ substrate $(10 \mu \mathrm{M})$ and incubated for $1 \mathrm{~h}$ at $37^{\circ} \mathrm{C}$ in a humidified air chamber with $5 \% \mathrm{CO}_{2}$ followed by immediate flow cytometric analysis (FL-2 channel). Caspase-3-like activity was expressed as mean fluorescence intensity from viable lymphocytes which were identified and gated by forward and side light-scattering properties.

\section{Immunocytochemistry double staining}

Cytospins were allowed to reach room temperature and the cells were fixed in paraformaledyde $4 \%$ for $15 \mathrm{~min}$. Antigen unmasking was performed by boiling the cytospins in $10 \mathrm{mM}$ citrate buffer for $15 \mathrm{~min}$ and then allowing cooling for $45 \mathrm{~min}$ at room temperature. Cells were permeabilised using ice-cold methanol for $10 \mathrm{~min}$ at $-20^{\circ} \mathrm{C}$. To avoid nonspecific staining, the cells smears were incubated in blocking buffer containing PBS, 5\% horse serum and $0.1 \%$ bovine serum albumin for $1 \mathrm{~h}$ at room temperature or overnight at $4^{\circ} \mathrm{C}$. The cell smears were incubated with goat anti-CD33 (Santa Cruz Biotechnology, 
Santa Cruz, CA, USA) diluted 1:100 in blocking buffer overnight at $4^{\circ} \mathrm{C}$. Cell smears were washed three times for 5 min in Tris-buffered saline (TBS); in the second wash $0.1 \%$ TWEEN 20 was added. Alkaline phosphatase-conjugated rabbit anti-goat (Sigma Aldrich) was diluted 1:100 in TBS containing $5 \%$ horse serum, and $0.1 \%$ bovine serum albumin was then added for $1 \mathrm{~h}$ at room temperature. The cell smears were washed three times for $5 \mathrm{~min}$ in TBS, with 0.1\% TWEEN 20 added in the second wash before staining using the alkaline substrate Fast Red for $10 \mathrm{~min}$. The slides were washed in running water for $10 \mathrm{~min}$, incubated in PBS for another $10 \mathrm{~min}$, followed by a second primary antibody. The antibodies used were either mouse anti-human Bcl-2 1:50 (clone 124; Dako Cytomation, Glostrup, Denmark) and proliferating cell nuclear antigen (PCNA) 1:500 (clone PC10; Calbiochem, Darmstadt, Germany) or mouse IgG as isotype control (Dako Cytomation), which were diluted in blocking buffer. The cell smears were incubated with the second primary antibody overnight at $4{ }^{\circ} \mathrm{C}$. Endogenous peroxide activity was quenched by incubating the slides with $0.3 \% \mathrm{H}_{2} \mathrm{O}_{2}$ in PBS for $30 \mathrm{~min}$. Following incubation with secondary antibody, biotinylated horse anti-goat IgG (Vector Laboratories, Inc., Burlingame, CA, USA) diluted in blocking buffer 1:100 for $1 \mathrm{~h}$, the cell smears were incubated with avidin-conjugated peroxidase substrate Vectasin elite $\mathrm{ABC}$ kit (Vector Laboratories, Inc.) for $90 \mathrm{~min}$. 3,3'Diaminobenzidine (Dako Cytomation) was used for colour development. The exposure time was 8 min for Bcl-2 staining, 5 min for the PCNA antibody and $10 \mathrm{~min}$ for the IgG isotype control antibody. The stained cytospins were counted in a blinded manner three times.

\section{Statistics}

Results are presented as median values with minimum and maximum values as range. Comparisons of data retrieved before and after provocation were made using Wilcoxon matched-pairs analysis. A p-value $<0.05$ was considered significant.

\section{RESULTS}

\section{Clinical parameters}

All patients provoked with allergen, but not those receiving saline, had an EAR defined as a $\geqslant 20 \%$ decrease in FEV1 within the first $3 \mathrm{~h}$ post-challenge. One of these patients also had a LAR, defined as $>15 \%$ decrease in FEV1 during 3-24 h postchallenge (table 1).

\section{BAL and blood cell data}

BAL recovery and cell viability did not differ in samples retrieved at baseline and after allergen or saline challenge. Although an increased BAL cell concentration was recorded in 10 out of the 12 patients, i.e. in both allergen- and salineexposed individuals compared with baseline, there was only a statistically significant $(\mathrm{p}<0.05)$ increase determined in those patients challenged with saline (table 2). The differential count of BAL cells revealed a significant increase in the percentage of eosinophils following allergen challenge $(p<0.05)$. However, both allergen and saline seemed to influence the amount of eosinophils in the lungs, since three out of five patients challenged with saline and five out of seven patients challenged with allergen had an increase in the proportion of BAL eosinophils compared with baseline levels. A tendency of a relative increase in BAL lymphocytes was observed in patients challenged with allergen. Here, the differential count showed an increase of lymphocytes in six out of seven patients challenged with allergen compared with only one out of five challenged with saline (table 2). The proportion of T-cells was $86 \%$ (75-91\%) among the BAL lymphocytes and 74\% (61-86\%) in PBL. The differential cell counts of whole blood revealed no change in the cellular composition at baseline and after allergen or saline challenge (data not included).

\section{Determination of apoptosis in BAL cells and PBL at baseline and after allergen/saline challenge}

Paired BAL lymphocytes and PBL from all individuals were tested for their apoptosis sensitivity at baseline and

\section{TABLE 2 Bronchoalveolar lavage cell count data before and after diluent or allergen exposure}

\begin{tabular}{|c|c|c|c|c|}
\hline & \multicolumn{2}{|c|}{ Diluent $^{\#}$} & \multicolumn{2}{|c|}{ Allergen } \\
\hline & Before & After & Before & After \\
\hline Viability \% & $94.5(82.5-99.0)$ & $94.0(86.0-98.7)$ & $93.6(83.0-95.0)$ & $94.5(87.7-100.0)$ \\
\hline Cell concentration $\times 10^{6} \cdot \mathrm{L}^{-1}$ & $71.0(68.8-90.3)$ & $194.4(97.8-393.0)^{*}$ & $114.7(44.6-131.2)$ & $154.3(82.4-216.1)$ \\
\hline Total cell count $\times 10^{6}$ & $12.5(11.5-16.7)$ & $52.5(13.5-86.7)$ & $18.3(8.7-25.0)$ & $24.0(15.0-47.10)$ \\
\hline Lymphocytes \% & $8.0(2.2-13.4)$ & $4.8(1.2-8.2)$ & $8.4(2.2-28.0)$ & $12.0(8.4-20.6)$ \\
\hline Total lymphocyte count $\times 10^{6}$ & $1.2(0.3-1.6)$ & $2.7(0.9-3.5)$ & $1.1(0.4-5.1)$ & $3.8(1.5-4.3)$ \\
\hline Neutrophils \% & $0.2(0.0-4.4)$ & $0.8(0.0-1.4)$ & $1.4(0.4-1.6)$ & $1.2(0.2-4.1)$ \\
\hline Total neutrophil count $\times 10^{6}$ & $0.02(0.00-0.53)$ & $0.2(0.0-0.4)$ & $0.2(0.1-0.4)$ & $0.3(0.1-1.0)$ \\
\hline Eosinophils \% & $0.4(0.0-2.8)$ & $2.5(0.0-18.8)$ & $0.2(0.0-2.4)$ & $2.4(0.0-42.2)^{*}$ \\
\hline Total eosinophil count $\times 10^{6}$ & $0.05(0.00-0.47)$ & $2.2(0.0-13.7)$ & $0.04(0.0-0.2)$ & $0.7(0.0-16.5)$ \\
\hline
\end{tabular}

Data are presented as median (minimum and maximum value range). ${ }^{*}: \mathrm{n}=5 ;{ }^{\bullet}: \mathrm{n}=7{ }^{+}{ }^{+}$. number in 10 visual fields, $\times 16$ magnification. ${ }^{\star}: \mathrm{p}<0.05$ 


\begin{tabular}{|c|c|c|c|c|c|}
\hline \multirow{3}{*}{$\begin{array}{l}\text { TABLE } 3 \\
\text { Challenge }\end{array}$} & \multicolumn{5}{|c|}{$\begin{array}{l}\text { Apoptosis susceptibility of bronchoalveolar } \\
\text { lavage lymphocytes in asthmatic subjects at } \\
\text { baseline and after allergen or saline inhalation }\end{array}$} \\
\hline & \multirow[t]{2}{*}{ Patient No. } & \multicolumn{2}{|c|}{ Before challenge } & \multicolumn{2}{|c|}{ After challenge } \\
\hline & & -TBT & +TBT & -TBT & + TBT \\
\hline \multirow[t]{8}{*}{ Allergen } & 1 & 15.9 & 43.3 & 19.0 & 25.8 \\
\hline & 4 & 11.0 & 38.6 & 8.5 & 20.5 \\
\hline & 5 & 10.4 & 52.2 & 5.8 & 23.6 \\
\hline & 7 & 9.2 & 62.5 & 5.1 & 42.4 \\
\hline & 8 & 9.4 & 33.9 & 12.3 & 23.5 \\
\hline & 10 & 10.6 & 42.2 & 7.6 & 18.2 \\
\hline & 11 & 8.4 & 34.8 & 6.5 & 15.3 \\
\hline & Median & 10.4 & 42.2 & 7.6 & 23.5 \\
\hline \multirow[t]{6}{*}{ Saline } & 2 & 18.4 & 37.1 & 4.4 & 48.5 \\
\hline & 3 & 6.6 & 41.5 & 9.7 & 43.2 \\
\hline & 6 & 12.4 & 37.8 & 7.9 & 14.5 \\
\hline & 9 & 9.6 & 26.6 & 9.1 & 32.3 \\
\hline & 12 & 12.5 & 38.2 & 16.1 & 36.8 \\
\hline & Median & 12.4 & 37.8 & 9.1 & 36.8 \\
\hline
\end{tabular}

Data are presented as percentage of annexin-V-positive bronchoalveolar lavage fluid cells. TBT: tributyltin.

post-challenge with either allergen or saline. Susceptibility to apoptosis induced by the mithochondrial pathway was investigated by stimulation with $2 \mu \mathrm{M}$ TBT in vitro, an agent that specifically induces mitochondrial permeability transition, loss of mitochondrial membrane potential, cytochrome C release and apoptosis [24, 25]. Apoptotic cells were identified

\begin{tabular}{|c|c|c|c|c|c|}
\hline \multirow{3}{*}{$\begin{array}{l}\text { TABLE } 4 \\
\text { Challenge }\end{array}$} & \multicolumn{5}{|c|}{$\begin{array}{l}\text { Apoptosis susceptibility of peripheral blood } \\
\text { lymphocytes from asthmatic subjects at baseline } \\
\text { and after allergen or saline inhalation }\end{array}$} \\
\hline & \multirow[t]{2}{*}{ Patient No. } & \multicolumn{2}{|c|}{ Before challenge } & \multicolumn{2}{|c|}{ After challenge } \\
\hline & & -TBT & + TBT & -TBT & + TBT \\
\hline \multirow[t]{8}{*}{ Allergen } & 1 & 1.4 & 35.7 & 3.0 & 47.0 \\
\hline & 4 & 3.3 & 35.5 & 8.1 & 47.0 \\
\hline & 5 & 2.8 & 25.2 & 4.9 & 24.2 \\
\hline & 7 & 1.6 & 58.6 & 2.3 & 11.3 \\
\hline & 8 & 2.4 & 21.4 & 6.2 & 25.7 \\
\hline & 10 & 3.5 & 54.9 & 5.6 & 80.0 \\
\hline & 11 & 2.6 & 69.9 & 2.7 & 62.9 \\
\hline & Median & 2.6 & 35.7 & 4.9 & 47.0 \\
\hline \multirow[t]{6}{*}{ Saline } & 2 & 2.6 & 51.4 & 3.9 & 40.5 \\
\hline & 3 & 1.9 & 46.7 & 6.8 & 51.8 \\
\hline & 6 & 3.3 & 75.1 & 8.1 & 32.6 \\
\hline & 9 & 4.0 & 28.6 & 3.9 & 24.6 \\
\hline & 12 & 2.5 & 56.4 & 3.9 & 75.8 \\
\hline & Median & 2.6 & 51.4 & 3.9 & 40.5 \\
\hline
\end{tabular}

Data are presented as percentage of annexin-V-positive peripheral blood lymphocytes. TBT: tributyltin. using annexin $\mathrm{V}$ staining and fluorescence-activated cell sorter analysis. The rate of spontaneous apoptosis among BAL lymphocytes and PBL was not altered by airway allergen or saline exposure (tables 3 and 4).

TBT exposure of BAL lymphocytes from patients in the allergen provocation group $(n=7)$ resulted in $42.2 \%$ (33.9$62.5 \%$ ) apoptotic BAL lymphocytes at baseline. After airway allergen challenge, the same treatment of the BAL cells resulted in a significant decrease in apoptotic lymphocytes $(p=0.023)$, since only $23.5 \%(15.3-42.4 \%)$ of the lymphocytes became apoptotic (table 3; fig. 1a). This phenomenon was not recorded in the group of patients who inhaled saline $(n=5)$. In this group, TBT induced apoptosis in $37.8 \%(26.6-41.5 \%)$ of the BAL lymphocytes obtained at baseline and in 36.8\% (14.5$48.5 \%$; nonsignificant) of the lymphocytes retrieved $24 \mathrm{~h}$ postsaline challenge (table 3 ; fig. $1 \mathrm{~b}$ ).

Inhalation of allergen or saline did not significantly alter the sensitivity of PBL to TBT-induced apoptosis. In the allergen provoked group, $35.7 \%$ (21.4-69.9\%) of the control lymphocytes were apoptotic upon treatment with $2 \mu \mathrm{M}$ TBT while the same treatment $24 \mathrm{~h}$ after challenge induced apoptosis in $47.0 \%$ (11.8-80.06\%; nonsignificant) of the lymphocytes (table 4; fig. 2a). In the group of patients inhaling saline, TBT exposure of PBL induced apoptosis in $51.4 \%(28.6-75.1 \%)$ of the lymphocytes at baseline while the same treatment $24 \mathrm{~h}$ after challenge triggered apoptosis in 40.5\% (24.6-75.8\%) of the PBL (nonsignificant; table 4; fig. 2b).

\section{Analysis of Bcl-2 and PCNA in BAL lymphocytes}

BAL lymphocytes (cytospins) from three subjects at baseline and post-allergen challenge, respectively, were stained for the expression of the anti-apoptotic protein $\mathrm{Bcl}-2$ and for PCNA (proliferation marker) together with an antibody against CD3. Allergen exposure increased the proportion of Bcl-2-expressing BAL lymphocytes, the majority being T-cells, from 54\% (47$63 \%)$ to $70 \%(59-77 \%)$ in the paired samples, i.e. at baseline and after allergen challenge from the same subject (fig. 3a). Data from unpaired samples from three additional patients at baseline (patient No. 9), following allergen exposure (patient No. 10) and after saline challenge (patient No. 12) were in line with the previous results $(55,71$ and $49 \%$ Bcl-2-expressing BAL lymphocytes in patient Nos 9, 10 and 12, respectively). One representative experiment of BAL cells from patient No. 11 stained for Bcl-2 at baseline and $24 \mathrm{~h}$ after challenge is also presented (fig. 3b-e).

All BAL lymphocytes analysed were PCNA negative at baseline and after saline and allergen challenge, indicating no proliferative activity among these cells (data not included).

\section{Detection of caspase-3 activity in BAL lymphocytes and $P B L$ at baseline and after airway allergen challenge}

To evaluate whether the pro-apoptotic enzyme caspase- 3 was activated in BAL lymphocytes and PBL, cells were loaded with a fluorigenic caspase- 3 substrate and the production of the cleavage product was monitored using flow cytometry. BAL lymphocytes possessed significantly higher endogenous caspase-3 activity than PBL ( $p=0.002$; fig. 4). However, allergen provocation did not significantly alter the basal caspase-3 levels in either BAL lymphocytes or PBL (fig. 5). 


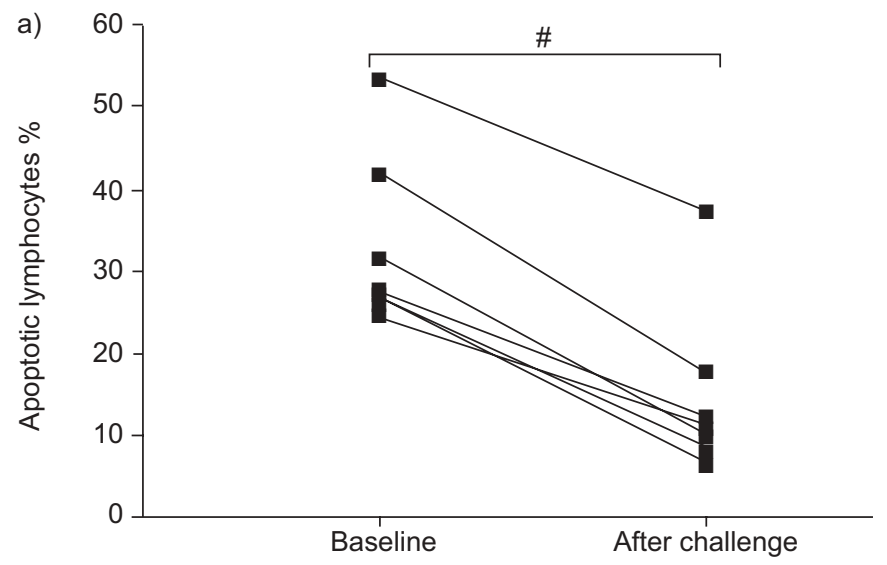

b)

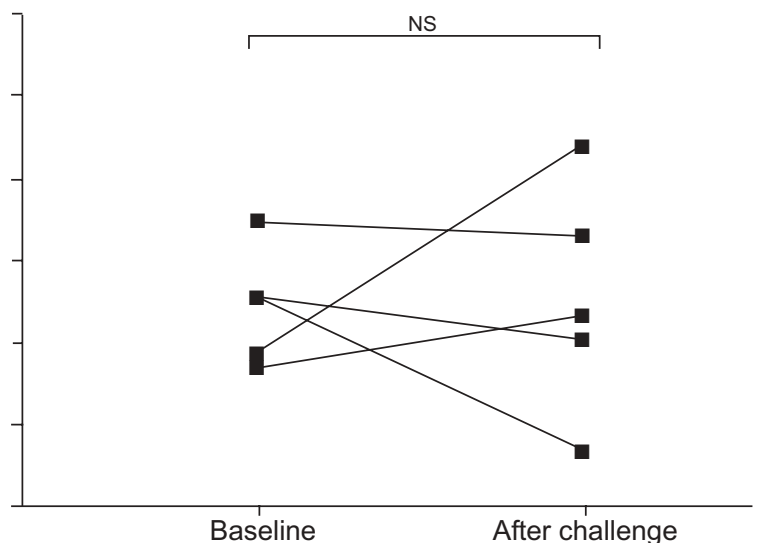

FIGURE 1. Apoptosis susceptibility of bronchoalveolar lavage (BAL) lymphocytes at baseline and after a) allergen or b) saline challenge. BAL cells were exposed to $2 \mu \mathrm{M}$ tributyltin (TBT) for $60 \mathrm{~min}$ followed by annexin-V staining and fluorescence-activated cell sorter analysis. Data depict the change in per cent apoptotic cells after TBT treatment compared to control cells, at baseline and after allergen or saline inhalation. NS: nonsignificant. ${ }^{*}: p<0.023$.

\section{DISCUSSION}

The present study reported that BAL lymphocytes from asthmatic subjects-exposed to allergen were significantly more resistant to mitochondrial-mediated apoptosis compared with nonallergen-exposed BAL lymphocytes from the same subjects. This decreased sensitivity to apoptosis was accompanied by an increase in the proportion of BAL lymphocytes expressing the $\mathrm{Bcl}-2$ protein. However, airway challenge with saline did not alter the sensitivity of BAL lymphocytes to TBTinduced apoptosis and neither did allergen or saline provocation influence the sensitivity of PBL to mitochondrial-mediated apoptosis. These data suggest that airway provocation with allergens triggers an inflammatory response, which results in the alteration of the apoptotic phenotype of lung lymphocytes but not of PBL. The observed discrepancy in apoptosis sensitivity between BAL and PBL following allergen challenge may reflect the different activation status of the cells in these two compartments; it is known that airway allergen challenge can cause an accumulation of activated allergen-specific lymphocytes in the airways [2, 30, 31]. The present results are concordant with previous studies of apoptosis in lymphocytes activated in vitro [32] and in BAL cells from patients with sarcoidosis [22].

The major proportion of lung lymphocytes are T-cells [33], which in asthma are characterised by a Th2-phenotype [1]. T-cells play a role in controlling chronic inflammation in asthma [34] and the number of T-cells infiltrating the bronchial airways is significantly increased in this disease [2, 31].

It is accepted that the increased numbers of mucosal T-cells is the result of an increased recruitment of these cells within the airways $[3,35,36]$. However, it is also likely that the number of $\mathrm{T}$-cells in the airways of asthmatic patients depends upon an increased survival of these cells. This hypothesis supports several studies in which it has been reported that cells engaged in the inflammatory asthmatic process are less apoptotic.

The potential role of the Fas receptor pathway in asthma has been intensively studied during recent years, albeit with contradictory results. Some studies have demonstrated a

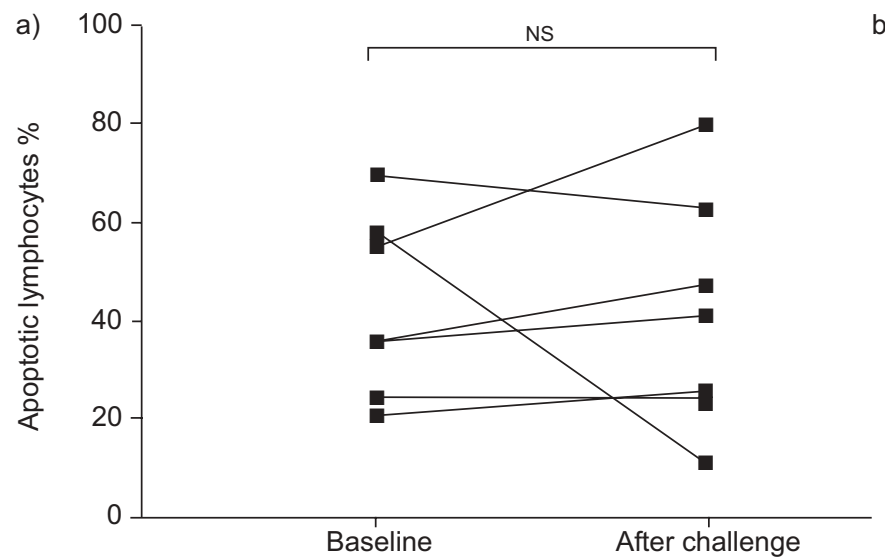

b)

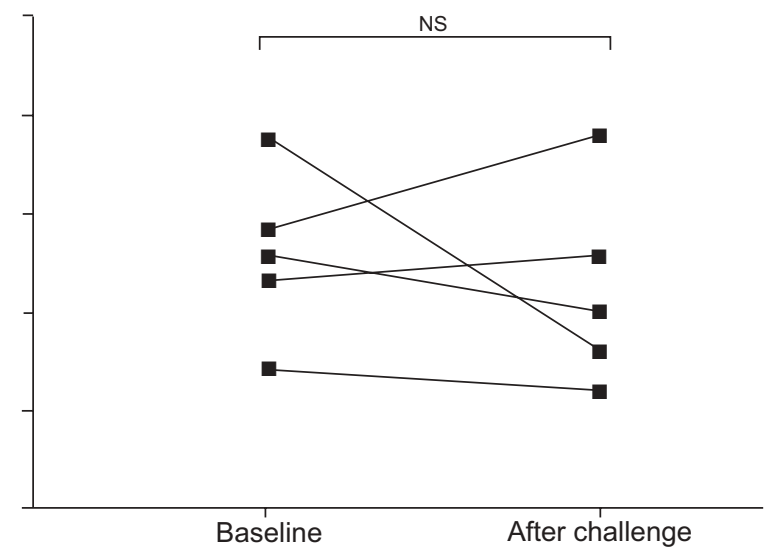

FIGURE 2. Apoptosis susceptibility of peripheral blood lymphocytes (PBL) at baseline and after a) allergen or b) saline challenge. Influence of tributyltin (TBT) on the induction of apoptosis in PBL of asthmatic subjects provoked by allergen (a) or saline (b). Data represent the change in per cent apoptotic cells after TBT treatment, before and after allergen challenge. NS: nonsignificant. 

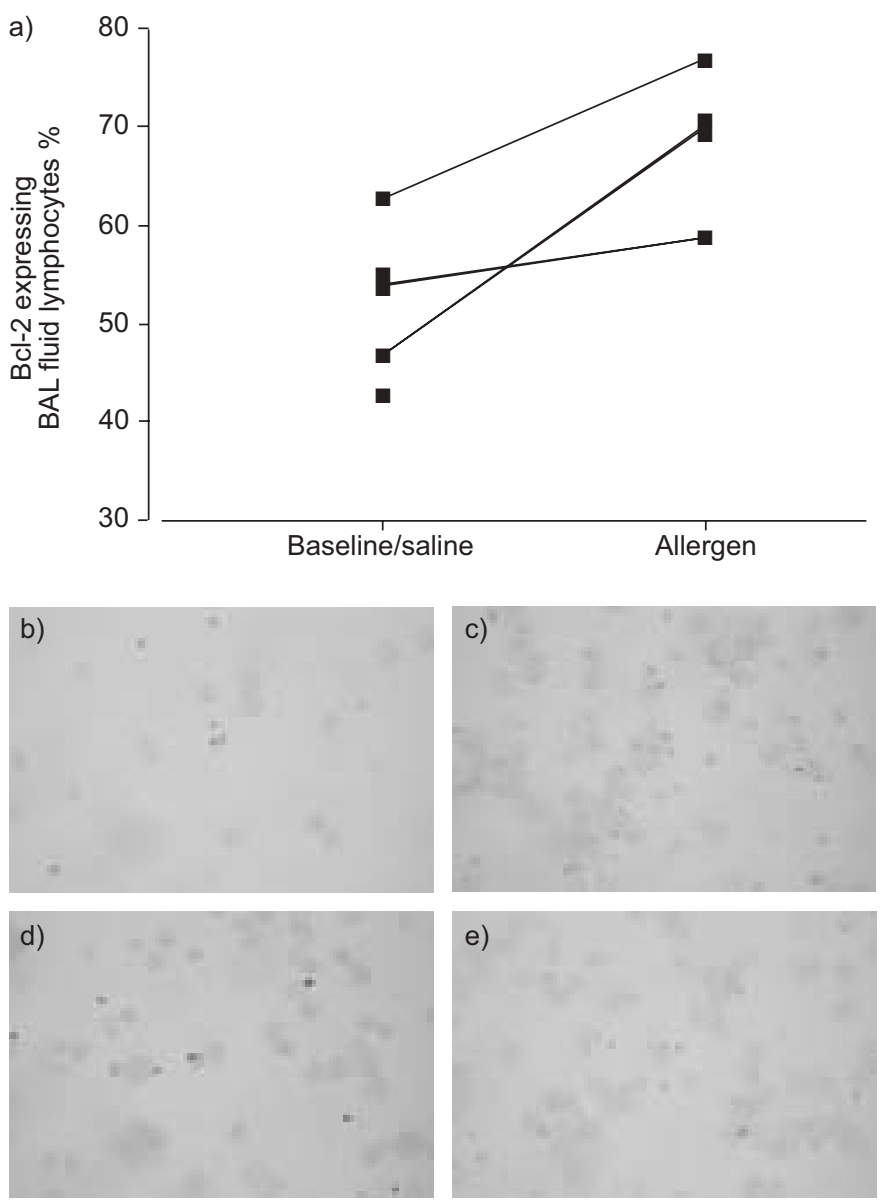

FIGURE 3. a) Bronchoalveolar lavage (BAL) fluid cells on cytospins from six subjects were stained using immunocytochemistry (ICC), for the expression of Bcl2. Paired samples (baseline and $24 \mathrm{~h}$ after airway allergen challenge from the same subject) are indicated with lines. Representative ICC experiments of $\mathrm{BCl}-2$ expression, darker stain (3,3'-diaminobenziding) in BAL fluid lymphocytes from one subject, at baseline (b) together with isotype-matched control (c) and $\mathrm{Bcl}-2$ expression after airway allergen challenge (d) and isotype-matched control stain in these cells (e).

decreased expression of Fas receptor or Fas ligand [6] in asthmatic subjects while other studies have reported an increased expression of Fas receptor and Fas ligand in asthmatic subjects $[37,38]$. Another study showed that T-cells from asthmatic subjects failed to undergo apotosis following Fas receptor ligation, although these cells express the same levels of Fas and Fas ligand as in nonasthmatic subjects [7].

The current authors were particularly interested to study the sensitivity of lymphocytes to mitochondrial-mediated apoptosis in asthma, since this pathway has been suggested to play a substantial role in downregulation of an immune response [10]. Therefore the present authors used TBT, a mitochondrial toxin that specifically triggers the mitochondrial pathway by loss of mitochondrial membrane potential and cytochrome C release [23-25].

The Bcl-2 family consists of both proteins that protect from mithochondrial-mediated apoptosis, such as Bcl-2 and Bcl-xL, and proteins that promote this apoptotic pathway, i.e. Bax, Bak,

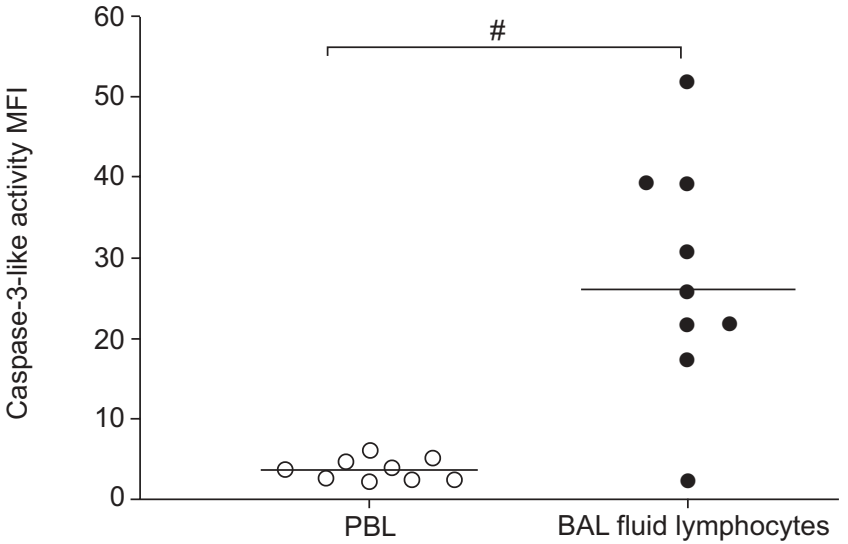

FIGURE 4. Baseline caspase-3-like activity in peripheral blood lymphocytes (PBL) and in bronchoalveolar lavage (BAL) fluid lymphocytes from asthmatic subjects. Cells were loaded with the cell-permeable substrate PhiPhilux $(10 \mu \mathrm{M})$ to detect caspase-3-like activity. Data are expressed as mean fluorescence intensity (MFI) and the lines indicate median values. ${ }^{*}: p=0.002$.

Bid and Bad [39]. The Bcl-2 protein is mainly localised in the mitochondria membrane where it blocks the release of cytochrome $\mathrm{C}$ and consequently caspase activation and apoptosis [39-41]. In the present study, an increase in resistance to mitochondrial-mediated apoptosis in BAL lymphocytes was observed following airway allergen challenge and this was associated with an increase in the proportion of Bcl-2-expressing lymphocytes. These data agree with several previous reports. In bronchial biopsies taken from asthmatic subjects, most T-cells do not appear to be apoptotic and express Bcl-2, suggesting that these cells may have the ability to live longer in the inflamed airways [4]. This was also confirmed by results obtained using an allergen-induced cutaneous late-phase response model [42]. Moreover, a recent study reported that cyclosporin treatment of asthmatic subjects prior to airway allergen challenge resulted in an increased apoptosis and reduced Bcl-2 expression among BAL lymphocytes [43]. In addition, Bcl-2 expression was increased in sputum mononuclear cells from asthmatic patients compared with patients with chronic obstructive pulmonary disease and healthy controls [6].

Sensitised individuals with allergic asthma develop an EAR 10-20 min after airway allergen challenge, which resolves after $\sim 1 \mathrm{~h}$. The bronchial constriction, increased vascular permeability and mucus production during EAR is caused by rapidly metabolised mediators, such as histamine, prostaglandins and leukotrienes, which are released by $\mathrm{IgE}$ cross-linked mast cells. Some individuals develop a LAR 3-4 h after challenge, which can persist for $\geqslant 24 \mathrm{~h}$. LAR is caused by the induced synthesis and release of inflammatory mediators including leukotrienes, chemokines and cytokines, which recruits other leukocytes, such as eosinophils and T-lymphocytes to the bronchial mucosa [44]. In the present study, airway allergen challenge induced EAR in all exposed subjects, although only one out of these seven individuals developed LAR. However, allergen exposure resulted in a significant rise in the proportion of $\mathrm{BAL}$ eosinophils, although an increase in lung eosinophils was also seen in three out of five subjects receiving saline. Interestingly, 


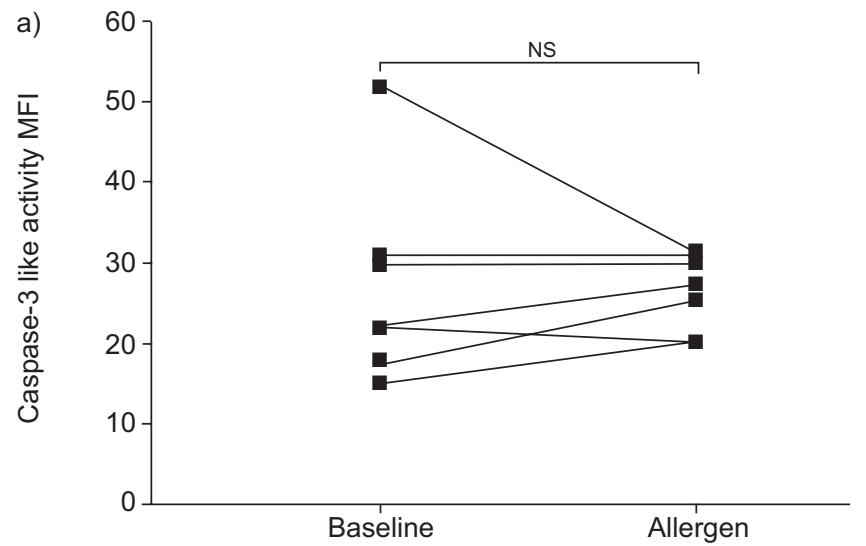

b)

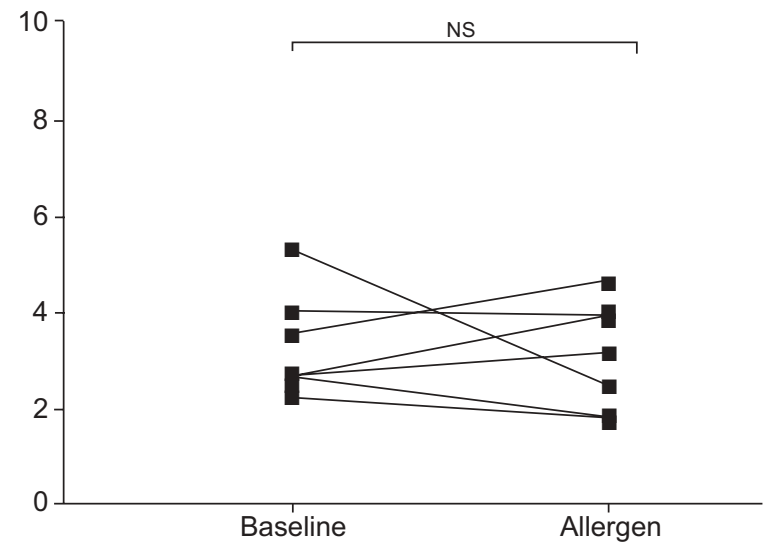

FIGURE 5. Caspase-3-like activity in a) bronchoalveolar lavage lymphocytes and b) peripheral blood lymphocytes at baseline and after allergen challenge. MFI: mean fluorescence intensity; NS: nonsignificant.

in six out of seven subjects, inhalation of airway allergen resulted in a nonsignificant increase in BAL lymphocytes and this tendency was not found among the saline-exposed individuals, suggesting an enhanced recruitment and/or survival of these cells after an allergen exposure which does not induce LAR $[45,46]$. The increased apoptosis resistance of BAL lymphocytes observed in the current study may reflect a cellular event that allergen, present in the normal milieu of the asthmatic individual, induces in airway lymphocytes. Decreased apoptosis sensitivity among these lymphocytes could contribute to the development of a subclinical inflammation in the bronchial mucosa resulting in thickening of the basement membrane and remodelling of the airways.

Several lines of evidence suggest additional nonapoptotic functions for traditionally pro-apoptotic caspases. Active caspase-3 participates in the differentiation of such diverse cell types as neurons, muscle cells, monocytes and erythroblasts [15-18]. Moreover, the proliferative machinery of T-cells appears to require active caspase- 8 and caspase- 3 , and the activation of caspase- 3 has been proposed to be essential for cell cycle progression in B-cells [19, 47-49]. Although it is established that caspases possess a nonapoptotic role in activated T-cells, it is not clear what initiates this activity and what the caspase-3 substrates are. However, Wu et al. [50] suggest that the transcription factors nuclear factor (NF)-ATc2 and NFAT, which are crucial for cytokine production and activation of T-cells, are substrates of caspase-3. BAL lymphocytes seem to have higher caspase-3-like activity, an observation that could be related to the higher activation status of lymphocytes in the lungs compared to peripheral lymphocytes [22]. This was further confirmed in the present study, in which viable BAL lymphocytes from asthmatic subjects had a significantly higher caspase-3-like activity than viable PBL from the same subjects. However, no PCNA expression was detected in BAL lymphocytes from the six subjects tested, suggesting that the elevated caspase- 3 activity observed was not associated with proliferation in these cells.

It is still unclear how cells with high caspase- 3 activity could be rescued from the proteolytic degradation machinery that is normally active in an apoptotic cell. There must be tight regulation of the apoptotic machinery in activated cells in order to prevent caspase- 3 from completing its commitment to degrade vital proteins. How such protection is achieved is not yet known, but compartmentalisation, conformational changes of the target proteins or protection via chaperones are possible mechanisms.

In conclusion, the current authors have demonstrated an alteration in the apoptotic machinery of bronchoalveoar lavage lymphocytes recovered from asthmatic subjects following airway allergen. This altered apoptotic phenotype may not be due to changes in the receptor inducible pathway but are definitely related to the mitochondrial apoptotic pathway. The present authors also recorded a significantly higher baseline level of caspase-3 activity in bronchoalveolar lavage lymphocytes from these asthmatic subjects compared with peripheral blood lymphocytes from the same subjects. These data indicate that airway inflammation in asthma is associated with a reduced apoptosis susceptibility, which may lead to an enhanced survival of lymphocytes in the bronchial mucosa and consequently prolonged inflammation.

\section{REFERENCES}

1 Kay $\mathrm{AB}$. The role of $\mathrm{T}$ lymphocytes in asthma. Chem Immunol Allergy 2006; 91: 59-75.

2 Azzawi M, Bradley B, Jeffery PK, et al. Identification of activated $\mathrm{T}$ lymphocytes and eosinophils in bronchial biopsies in stable atopic asthma. Am Rev Respir Dis 1990; 142: 1407-1413.

3 Bentley AM, Menz G, Storz C, et al. Identification of T lymphocytes, macrophages, and activated eosinophils in the bronchial mucosa in intrinsic asthma. Relationship to symptoms and bronchial responsiveness. Am Rev Respir Dis 1992; 146: 500-506.

4 Vignola AM, Chanez P, Chiappara G, et al. Evaluation of apoptosis of eosinophils, macrophages, and T lymphocytes in mucosal biopsy specimens of patients with asthma and chronic bronchitis. J Allergy Clin Immunol 1999; 103: 563-573.

5 Cormican L, O'Sullivan S, Burke CM, Poulter LW. IFNgamma but not IL-4 T cells of the asthmatic bronchial wall 
show increased incidence of apoptosis. Clin Exp Allergy 2001; 31: 731-739.

6 Hamzaoui A, Hamzaoui K, Salah H, Chabbou A. Lymphocytes apoptosis in patients with acute exacerbation of asthma. Mediators Inflamm 1999; 8: 237-243.

7 Jayaraman S, Castro M, O'Sullivan M, Bragdon MJ, Holtzman MJ. Resistance to Fas-mediated T cell apoptosis in asthma. J Immunol 1999; 162: 1717-1722.

8 Lamb JP, James A, Carroll N, Siena L, Elliot J, Vignola AM. Reduced apoptosis of memory T-cells in the inner airway wall of mild and severe asthma. Eur Respir J 2005; 26: 265-270.

9 Krueger A, Fas SC, Baumann S, Krammer PH. The role of CD95 in the regulation of peripheral T-cell apoptosis. Immunol Rev 2003; 193: 58-69.

10 Hildeman DA, Zhu Y, Mitchell TC, Kappler J, Marrack P. Molecular mechanisms of activated $\mathrm{T}$ cell death in vivo. Curr Opin Immunol 2002; 14: 354-359.

11 Green DR, Droin N, Pinkoski M. Activation-induced cell death in T cells. Immunol Rev 2003; 193: 70-81.

12 Budd RC. Activation-induced cell death. Curr Opin Immunol 2001; 13: 356-362.

13 Krammer PH. CD95's deadly mission in the immune system. Nature 2000; 407: 789-795.

14 Green DR. Overview: apoptotic signaling pathways in the immune system. Immunol Rev 2003; 193: 5-9.

15 Sordet O, Rebe C, Plenchette S, et al. Specific involvement of caspases in the differentiation of monocytes into macrophages. Blood 2002; 100: 4446-4453.

16 Fernando P, Brunette S, Megeney LA. Neural stem cell differentiation is dependent upon endogenous caspase 3 activity. FASEB J 2005; 19: 1671-1673.

17 Zermati Y, Garrido C, Amsellem S, et al. Caspase activation is required for terminal erythroid differentiation. J Exp Med 2001; 193: 247-254.

18 Fernando P, Kelly JF, Balazsi K, Slack RS, Megeney LA. Caspase 3 activity is required for skeletal muscle differentiation. Proc Natl Acad Sci USA 2002; 99: 11025-11030.

19 Alam A, Cohen LY, Aouad S, Sekaly RP. Early activation of caspases during $\mathrm{T}$ lymphocyte stimulation results in selective substrate cleavage in nonapoptotic cells. J Exp Med 1999; 190: 1879-1890.

20 Kennedy NJ, Kataoka T, Tschopp J, Budd RC. Caspase activation is required for $\mathrm{T}$ cell proliferation. $J$ Exp Med 1999; 190: 1891-1896.

21 Launay S, Hermine O, Fontenay M, Kroemer G, Solary E, Garrido C. Vital functions for lethal caspases. Oncogene 2005; 24: 5137-5148.

22 Stridh H, Planck A, Gigliotti D, Eklund A, Grunewald J. Apoptosis resistant bronchoalveolar lavage (BAL) fluid lymphocytes in sarcoidosis. Thorax 2002; 57: 897-901.

23 Stridh H, Gigliotti D, Orrenius S, Cotgreave I. The role of calcium in pre- and postmitochondrial events in tributyltin-induced T-cell apoptosis. Biochem Biophys Res Commun 1999; 266: 460-465.

24 Stridh H, Kimland M, Jones DP, Orrenius S, Hampton MB. Cytochrome $\mathrm{c}$ release and caspase activation in hydrogen peroxide- and tributyltin-induced apoptosis. FEBS Lett 1998; 429: 351-355.

25 Stridh H, Orrenius S, Hampton MB. Caspase involvement in the induction of apoptosis by the environmental toxicants tributyltin and triphenyltin. Toxicol Appl Pharmacol 1999; 156: 141-146.

26 Gyllfors P, Kumlin M, Dahlen SE, Gaber F, Ehrs PO, Dahlen B. Relation between bronchial responsiveness to inhaled leukotriene D4 and markers of leukotriene biosythesis. Thorax 2005; 60: 902-908.

27 Dahlen B, Zetterstrom O, Bjorck T, Dahlen SE. The leukotriene-antagonist ICI-204,219 inhibits the early airway reaction to cumulative bronchial challenge with allergen in atopic asthmatics. Eur Respir J 1994; 7: 324-331.

28 Katchar K, Wahlstrom J, Eklund A, Grunewald J. Highly activated T-cell receptor AV2S3(+) CD4(+) lung T-cell expansions in pulmonary sarcoidosis. Am J Respir Crit Care Med 2001; 163: 1540-1545.

29 Eklund A, Blaschke E. Relationship between changed alveolar-capillary permeability and angiotensin converting enzyme activity in serum in sarcoidosis. Thorax 1986; 41: 629-634.

30 Jeffery PK, Wardlaw AJ, Nelson FC, Collins JV, Kay AB. Bronchial biopsies in asthma. An ultrastructural, quantitative study and correlation with hyperreactivity. Am Rev Respir Dis 1989; 140: 1745-1753.

31 Robinson DS, Bentley AM, Hartnell A, Kay AB, Durham SR. Activated memory T helper cells in bronchoalveolar lavage fluid from patients with atopic asthma: relation to asthma symptoms, lung function, and bronchial responsiveness. Thorax 1993; 48: 26-32.

32 Muller M, Grunewald J, Gigliotti D, Eklund A, Stridh H. T-cell activation and the development of an apoptosisresistant CD45RO+ T-cell population. Scand J Immunol 2003; 57: 254-260.

33 Krug N, Erpenbeck VJ, Balke K, et al. Cytokine profile of bronchoalveolar lavage-derived CD4(+), CD8(+), and gammadelta $\mathrm{T}$ cells in people with asthma after segmental allergen challenge. Am J Respir Cell Mol Biol 2001; 25: 125-131.

34 Larche M, Robinson DS, Kay AB. The role of T lymphocytes in the pathogenesis of asthma. J Allergy Clin Immunol 2003; 111: 450-463.

35 Jeffery PK, Laitinen A, Venge P. Biopsy markers of airway inflammation and remodelling. Respir Med 2000; 94: Suppl F, S9-S15.

36 Busse WW, Lemanske RF Jr. Asthma. N Engl J Med 2001; 344: 350-362.

37 Druilhe A, Wallaert B, Tsicopoulos A, et al. Apoptosis, proliferation, and expression of $\mathrm{Bcl}-2$, Fas, and Fas ligand in bronchial biopsies from asthmatics. Am J Respir Cell Mol Biol 1998; 19: 747-757.

38 Krug N, Tschernig T, Balke K, et al. Enhanced expression of fas ligand (CD95L) on $\mathrm{T}$ cells after segmental allergen provocation in asthma. J Allergy Clin Immunol 1999; 103: 649-655.

39 Fadeel B, Zhivotovsky B, Orrenius S. All along the watchtower: on the regulation of apoptosis regulators. FASEB J 1999; 13: 1647-1657.

40 Fadeel B, Orrenius S. Apoptosis: a basic biological phenomenon with wide-ranging implications in human disease. J Intern Med 2005; 258: 479-517.

41 Li P, Nijhawan D, Budihardjo I, et al. Cytochrome $\mathrm{c}$ and dATP-dependent formation of Apaf-1/caspase-9 complex initiates an apoptotic protease cascade. Cell 1997; 91: 479-489. 
42 Ying S, Meng Q, Taborda-Barata L, Kay AB. Association of apoptosis of neutrophils and eosinophils and their ingestion by macrophages with resolution of the allergeninduced cutaneous late-phase response in atopic human subjects. Proc Assoc Am Physicians 1997; 109: 42-50.

43 Ying S, Khan LN, Meng Q, Barnes NC, Kay AB. Cyclosporin A, apoptosis of BAL T-cells and expression of Bcl-2 in asthmatics. Eur Respir J 2003; 22: 207-212.

44 Oldfield WL, Kay AB, Larche M. Allergen-derived T cell peptide-induced late asthmatic reactions precede the induction of antigen-specific hyporesponsiveness in atopic allergic asthmatic subjects. J Immunol 2001; 167: 1734-1739.

45 O'Byrne PM, Dolovich J, Hargreave FE. Late asthmatic responses. Am Rev Respir Dis 1987; 136: 740-751.

46 Gonzalez MC, Diaz P, Galleguillos FR, Ancic P, Cromwell O, Kay AB. Allergen-induced recruitment of bronchoalveolar helper (OKT4) and suppressor (OKT8)
T-cells in asthma. Relative increases in OKT8 cells in single early responders compared with those in late-phase responders. Am Rev Respir Dis 1987; 136: 600-604.

47 Wilhelm S, Wagner H, Hacker G. Activation of caspase-3like enzymes in non-apoptotic T cells. Eur J Immunol 1998; 28: 891-900.

48 Beisner DR, Chu IH, Arechiga AF, Hedrick SM, Walsh CM. The requirements for Fas-associated death domain signaling in mature $\mathrm{T}$ cell activation and survival. J Immunol 2003; 171: 247-256.

49 Woo M, Hakem R, Furlonger C, et al. Caspase-3 regulates cell cycle in B cells: a consequence of substrate specificity. Nat Immunol 2003; 4: 1016-1022.

$50 \mathrm{Wu}$ W, Misra RS, Russell JQ, Flavell RA, Rincon M, Budd RC. Proteolytic regulation of NFATc2 and NFAT activity by caspase-3. J Biol Chem 2006; 281: 10682-10690. 